\title{
The use of negative pressure therapy for the treatment of lower-extremity wounds.
}

\author{
Atef Elsayed Emam ${ }^{1}$, Abdel Naser Khallaf ${ }^{2}$, Attia Mohamed Attia ${ }^{1}$
}

\author{
CorrespondingAuthor: \\ Attia Mohamed Attia, \\ Attiamohamedattia0@gmail.com
}

Received for publication, Febuary 27, 2020; Accepted, May 8, 2020; published online, May 9, 2020.

Copyright 2020 The Authors published by Al-Azhar University, Faculty of Medicine, Cairo, Egypt. All rights reserved. This an openaccess article distributed under the legal terms, where it is permissible to download and share the work provided it is properly cited. The work cannot be changed in anyway or used commercially.

doi:1․21608/aimj.2020.24523.1151

${ }^{1}$ Plastic and reconstructive surgery, Military Medical Academy.

${ }^{2}$ Plastic and Burn surgery Department, Faculty of Medicine, AlAzhar University, Cairo, Egypt.

\begin{abstract}
Background: lower extremity wounds with exposed bone, tendon or orthopedic hardware present a difficult treatment challenge

Objective: The purpose of this study is to assess the role of the vacuum assisted closure (VAC) therapy in the management of lower extremity wounds.

Material and methods: A prospective analytic cohort study was conducted among 15 patient referred for reconstruction of lower extremity wounds. The study was conducted between January 2019 to June 2019. The wounds were inspected, surgical debridement was done if needed, and the VAC dressings were changed every 72 hours. Primary outcome was wound healing and granulation tissue formation. Secondary outcome was wound infection and wound size .
\end{abstract}

Results: Vacuum- assisted closure therapy greatly decreases the surface area of the wound. Profuse granulation tissue formed rapidly, covering the bone and hardware. There was no statistically significant difference between the included patients regarding the pattern of wound infection pre and after negative pressure therapy $(\mathrm{p}=0.655)$. Results were both functionally and aesthetically satisfactory.

Conclusion: VAC therapy appears to be a simple and more effective than conventional dressings for the management of difficult wound in terms of reduction in wound volume, depth, treatment duration and cost minimize the number of local and free-flap transfers.

Key words: VAC; NPWT; Lower Extremity wounds; Complex wounds.

Disclosure: The authors have no financial interest to declare in relation to the content of this article. The Article Processing Charge was paid for by the authors. 
that take a long time to heal, fail to heal or recur. They are very common in industrialized countries and cause significant pain and discomfort. The true incidence and economic impact of chronic wounds are difficult to assess because of the wide range of causative diseases and available treatment options. ${ }^{5}$

Non-healing wounds affect about 3 to 6 million people in the United States, with persons 65 years and older accounting for $85 \%$ of these events. Nonhealing wounds result in enormous health care expenditures, with the total cost estimated at more than $\$ 3$ billion per year. ${ }^{6}$

In this study the author assess the role of the vacuum assisted closure (VAC) therapy in the management of lower extremity wounds.

\section{Material and Methods}

\section{Study design:}

This study is a prospective cohort study, consisted of 15 patients who were subjected for reconstruction of lower extremity wounds.

The study was conducted between January 2019 and June 2019. This study has been executed at the Plastic Surgery Department, El helmeya Armed Forces Hospital, Plastic and reconstructive department and Sayed Galal University Hospitals, Faculty of Medicine, Al-Azhar University, Cairo, Egypt.

\section{Inclusion Criteria:}

Patients aged more than 18 years old with Lower extremity wounds in an anatomical position feasible for creating an air-tight seal for NPWT.

\section{Exclusion Criteria:}

Patients aged less than 18 years old with complex wound anywhere other than lower limb. All patients gave written informed consent.

\section{Ethical approval :}

An approved was obtained from the Ethical Research Board (ERB) of the Faculty of Medicine, Al-Azhar University, Cairo, Egypt. Prior to study proceeding, all patients assigned informed consents after the obvious explanation of the possible adverse events.

\section{VAC procedure :}

Any dressings from the wound were removed and discarded. A swab for microbiology culture and sensitivity was taken before wound irrigation with normal saline. In case of necrotic tissues surgical debridement was done, and adequate haemostasis was achieved (Figure 1A,1B).

Prior to application of the drape, it was essential to prepare the peri-wound skin and ensure that it was dry.

Sterile, double layers of $1 \mathrm{~cm}$ thickness open-pore foam into which was embedded an evacuation tube of 16 or $18 \mathrm{Fr}$. were gently placed into the wound cavity. Then the tube was connected to a container of vacuum pump.

The site was then sealed with an adhesive drape covering the foam and all around the tube and at least three to five centimeters of the surrounding healthy tissue to ensure an airtight seal. Controlled intermittent pressure was applied to the wound.

The vacuum pump delivers a negative pressure of $-125 \mathrm{mmHg}$. The cycle was of one hour on and one hour off .

After the VAC dressing changed. The wound was washed thoroughly with normal saline, antiseptic solution and VAC was re-applied in most cases at bedside. The same routine was continued until full healing or satisfactory clean, granulating wound bed was obtained for Skin grafting or local flap. Figure $(2,3 \& 4)$

Data were collected and Demographic information collected includes age, sex and co-morbid condition. Information noted for wound includes site and etiology of the wound, size before and after application of VAC.

Mean, frequency, ratio and percentages were calculated and data were inference also in the form of tables.

\section{Statistical analysis of the data:-}

Statistical analysis was performed using SPSS software version 23 for Windows (SPSS Inc., Chicago, IL, USA). The figures were renovated using GraphPad Prism (GraphPad Software, Inc, San Diego) software version 7. Continuous non-normally distributed data were reported using median and range. Subsequently, categorical variables were expressed using number and percentage and paired categorical data were compared using Wilcoxon Signed Ranks Test. The overall statistically significant difference was established at $\mathrm{p}<0.05$.
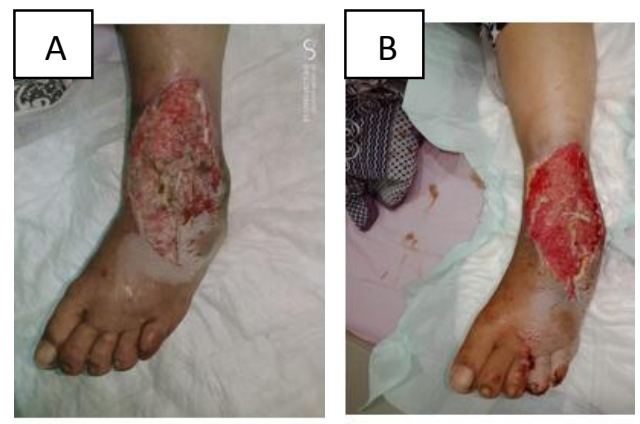

Figure $1(\mathrm{~A} \& \mathrm{~B})$

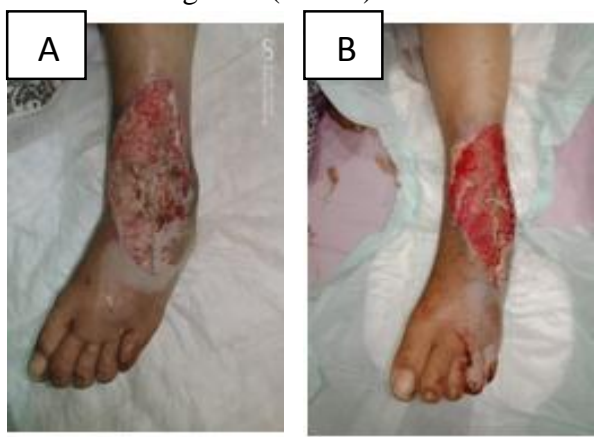

Figure $2(\mathrm{~A} \& \mathrm{~B})$ 
Emam, et al. Negative pressure therapy in wounds
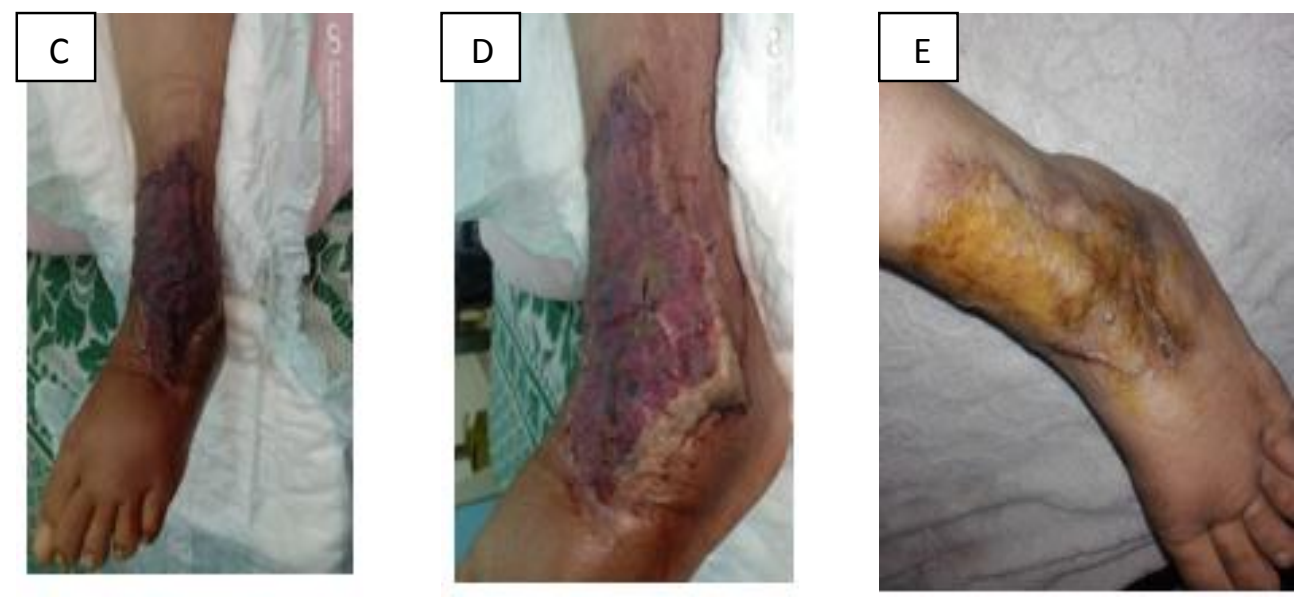

Figure $2(\mathrm{C}, \mathrm{D} \& \mathrm{E})$
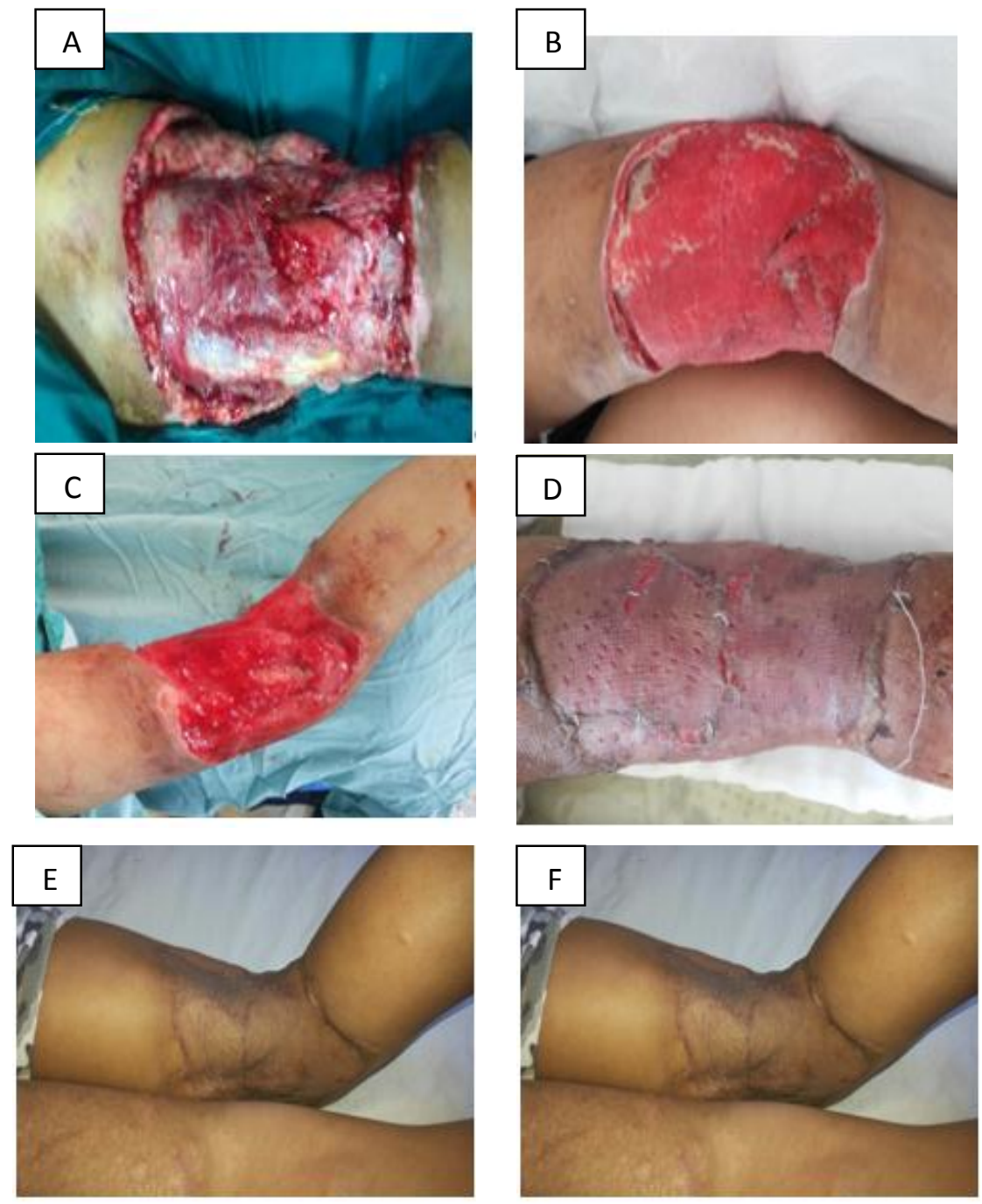

Figure $3(\mathrm{~A}, \mathrm{~B}, \mathrm{C}, \mathrm{D}, \mathrm{E} \& \mathrm{~F})$ 

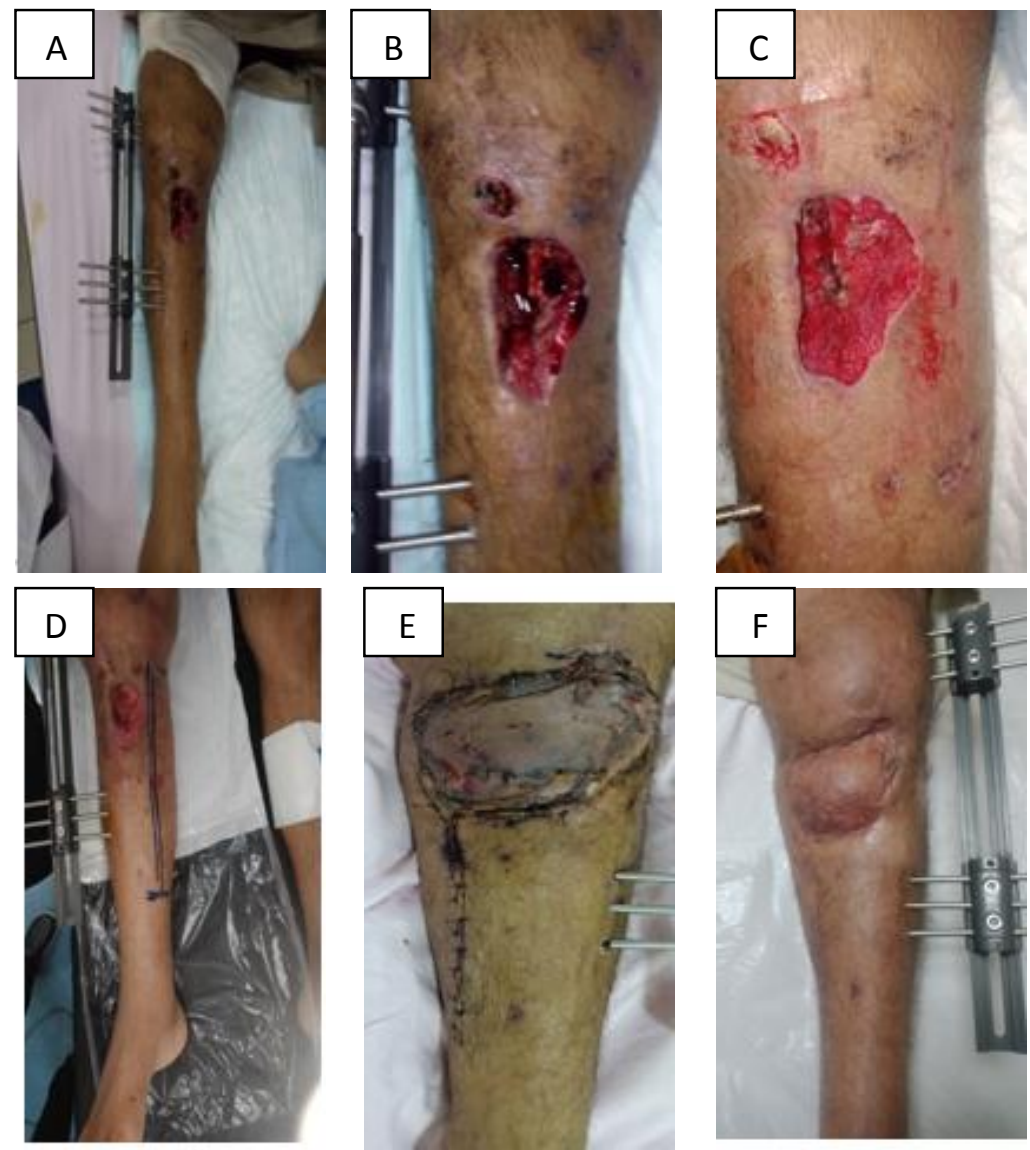

Figure 4 (A, B, C, D, E \& F)

\begin{tabular}{|c|c|}
\hline \multicolumn{2}{|r|}{ Figure 1} \\
\hline A & Degloving injury of right foot before surgical debridement \\
\hline B & The wound after surgical debridement. \\
\hline \multicolumn{2}{|r|}{ Figure 2} \\
\hline A & Crushed injury of lower $1 / 3$ of right leg and foot after RTA \\
\hline B & The wound after surgical debridement. \\
\hline C and D & The wound after $1^{\text {st }}$ dressing following Split thickness skin graft. \\
\hline E & Two months follow up after Split thickness skin graft. \\
\hline \multicolumn{2}{|r|}{ Figure 3} \\
\hline A & Skin and soft tissue loss of right popliteal fossa after Road traffic accident. \\
\hline B & The wound after two weeks on VAC dressing. \\
\hline C & The wound after three weeks on VAC dressing. \\
\hline D & The wound after early split thickness skin graft. \\
\hline E & The wound after two months follow up during flexion. \\
\hline $\mathbf{F}$ & The wound after two months follow up during Extension. \\
\hline \multicolumn{2}{|r|}{ Figure 4} \\
\hline$A$ and $B$ & $\begin{array}{l}\text { Contaminated complex wound of upper } 1 / 3 \text { of right leg associated with fracture tibia } \\
\text { treated by External fixator. }\end{array}$ \\
\hline C & The wound after one week on VAC dressing. \\
\hline D & Marking before flap elevation. \\
\hline $\mathbf{E}$ & Medial head of gastrocnemius flap was done. \\
\hline$F$ & Complete healing after two months follow up. \\
\hline
\end{tabular}

Table (1) Figure legend: 
Emam, et al. Negative pressure therapy in wounds

Results

The study was conducted for fifteen patients with complex wounds admitted to the Elhelmeya Armed Forces Hospital, Plastic and Reconstructive surgery department.

The study included 9 males $(60 \%)$ and 6 females $(40 \%)$. with a median age of $27(6-55)$ years. Out of the included patients, there were three (20\%) patients suffered from diabetes, a case $(6.6 \%)$ of systemic lupus erythematosus, and three (20\%) hypertensive cases. (Table 2, Figure 5 and 6). There were 8 (53.3\%) patients had lower extremity wound as a result of trauma. Additionally, two (13.3\%) patients had lower limb wound as a result of diabetic foot, whereby one $(6.6 \%)$ patient had such wound as a sequel of fascio-cutaneous flap failure. Eventually, two $(13.3 \%)$ patients had lower extremity wound after abscess drainage, whereas one $(6.6 \%)$ case had lower limb wound as a result of cellulitis (Table 3,
Figure 7). In our cohort, the median wound size was $15(3-30) \mathrm{cm} 2$. In this concern, the most common wound site was the foot, $6(40 \%)$ cases, thigh 4 (26.6) cases and legs $3(20 \%)$ cases, respectively. There were an equal proportion of patients who had knee and ankle wound, (6.6\%). Figures 8, 9 and Table 4). Pre-negative pressure therapy, there were $8(53.3 \%)$ patients with positive wound infection. After such therapy, one of them $(6.6 \%)$ experienced negative wound infection, whereas $7(46.6 \%)$ cases still had positive wound infection. There was no statistically significant difference between the included patients regarding the pattern of wound infection pre and after negative pressure therapy $(\mathrm{p}=0.655)$ (Table 5).

As for the fate of wound after negative pressure therapy, one case $(6.6 \%)$ experienced spontaneous healing of the wound, whereas nine $(60 \%)$ and five $(33.33 \%)$ cases necessitated graft and flap at the site of the wound, respectively. (Figure 10 and Table 6).

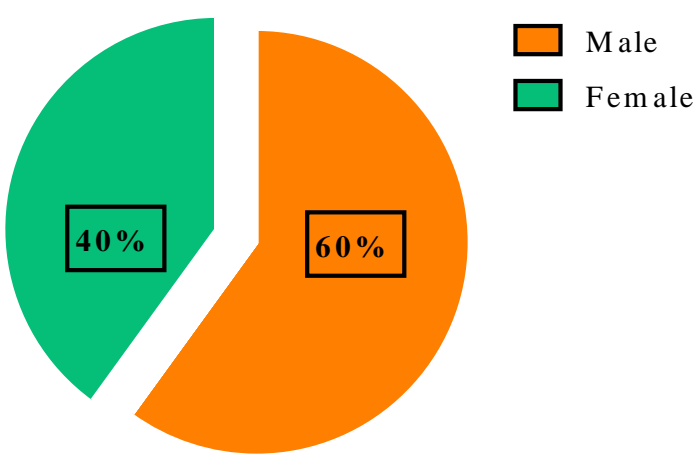

Figure (5): Distribution of studied sample according to sex. 


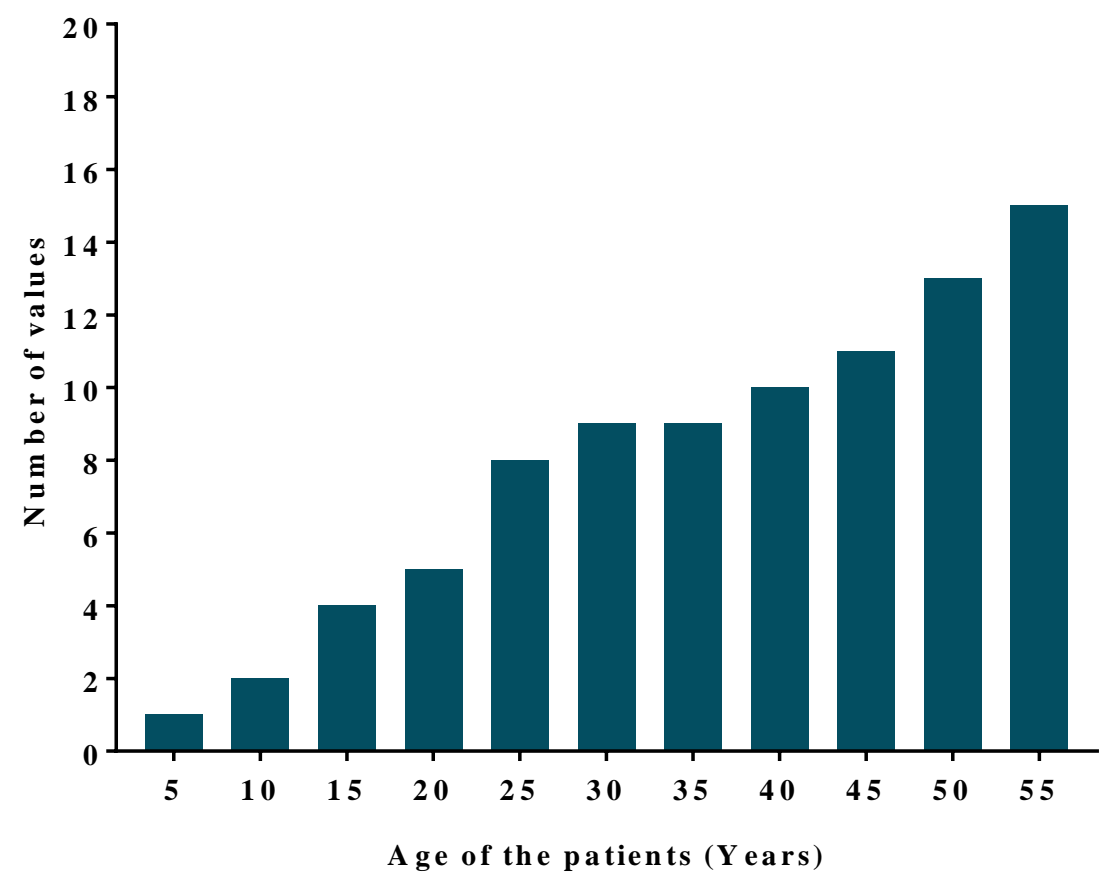

Figure (6): Histogram displayed the age distribution among the included patients

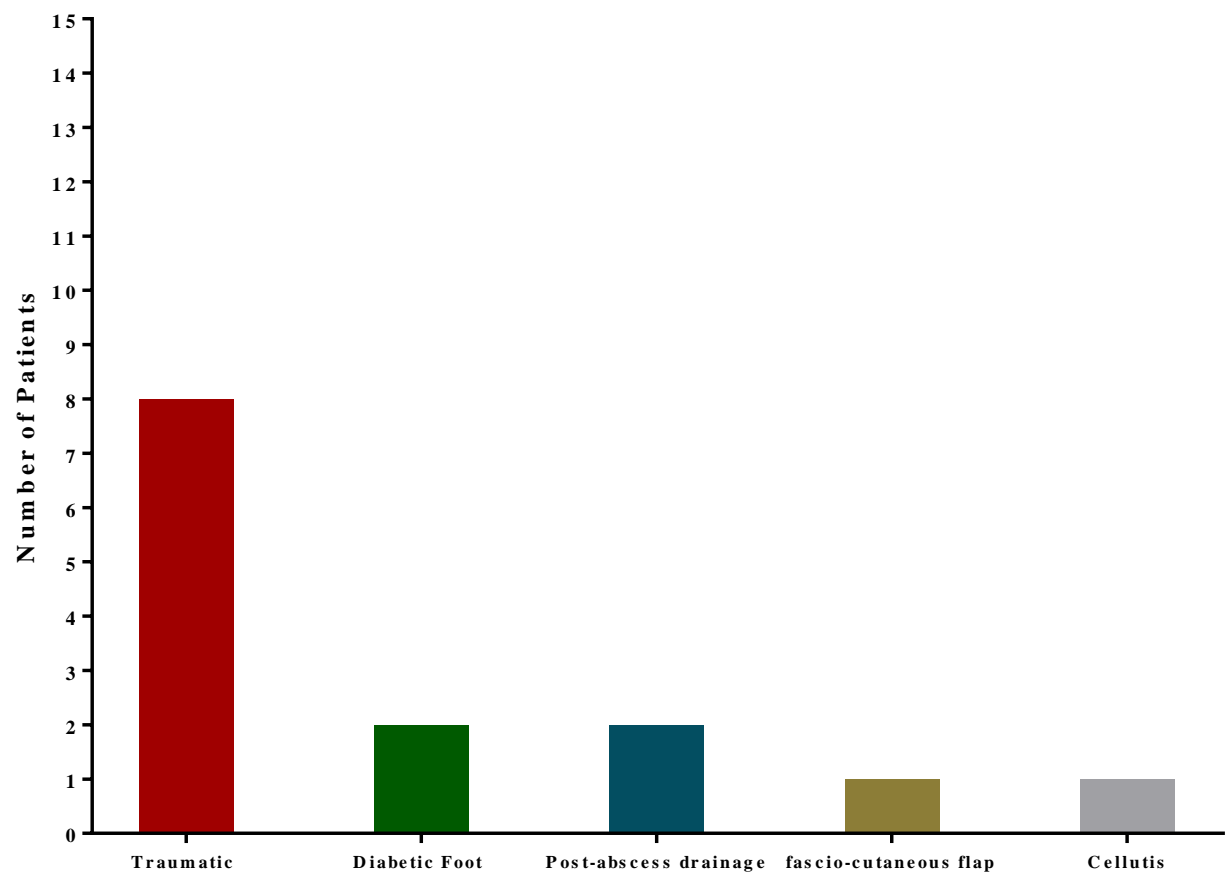

Figure (7): Bar chart displayed causes of lower extremity wounds among the included patients 


\section{Emam, et al. Negative pressure therapy in wounds}

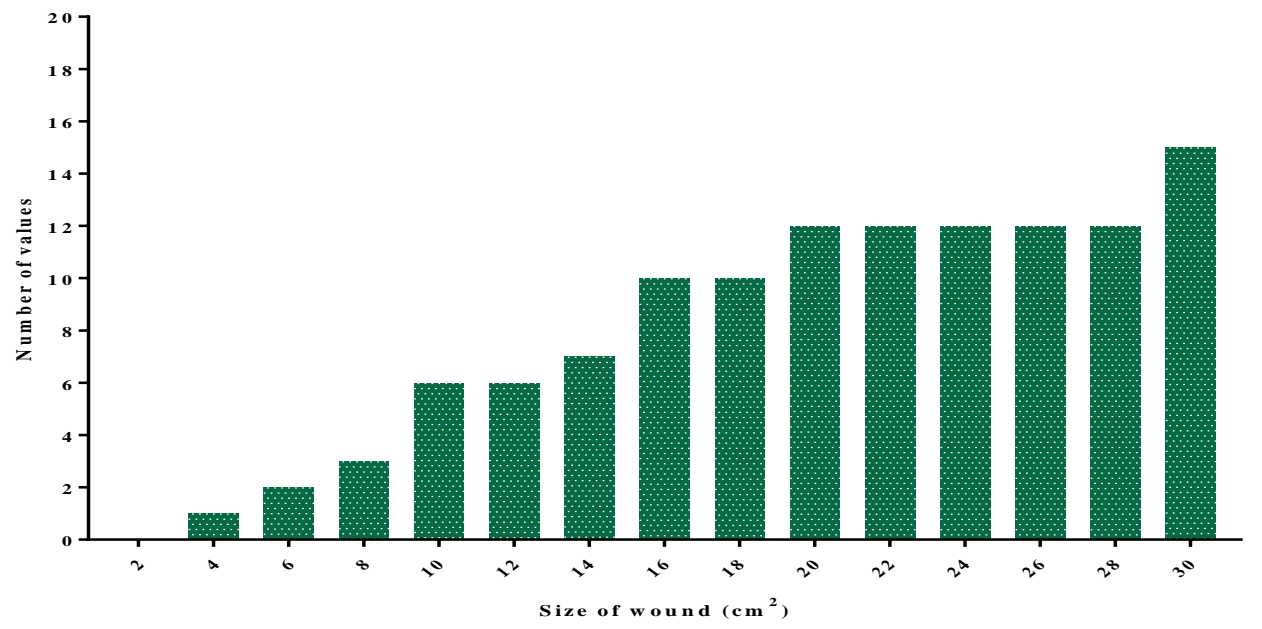

Figure (8): Histogram displayed the size of wounds among the included patients

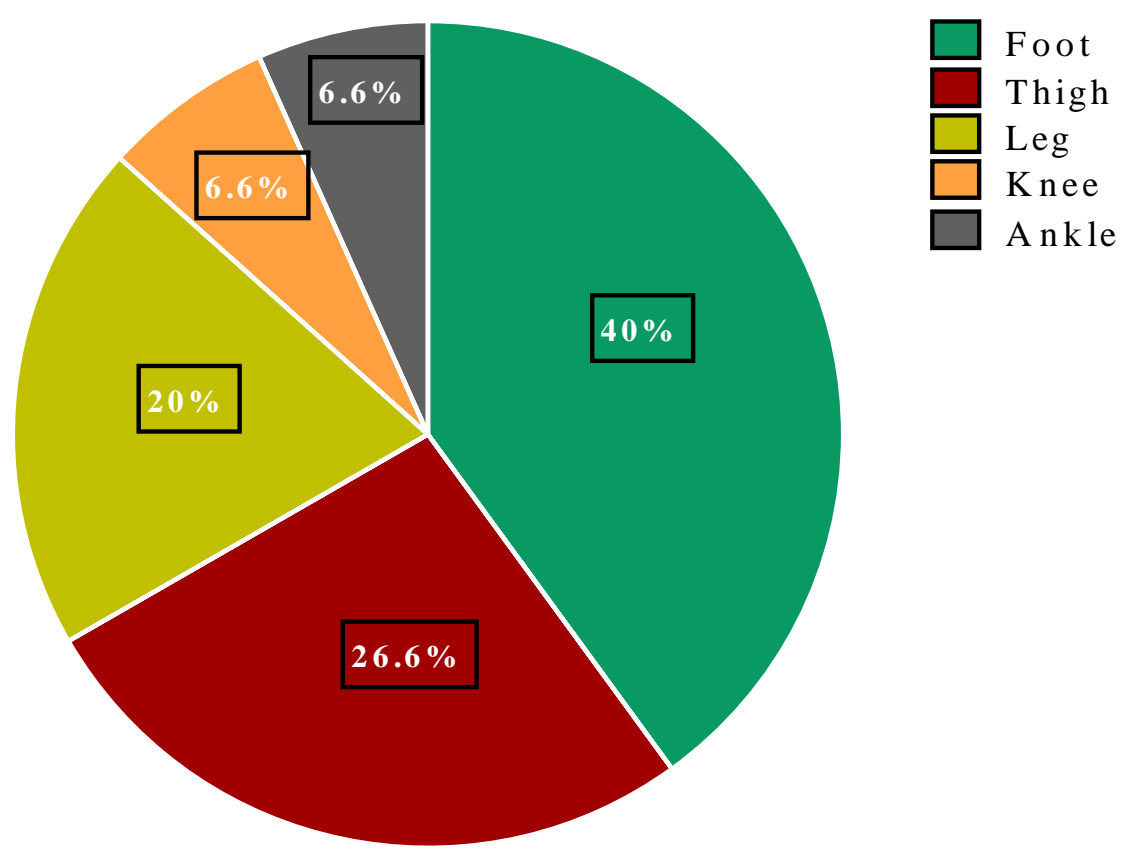

Figure (9): Pie chart displayed the site of the wound among the included patients 


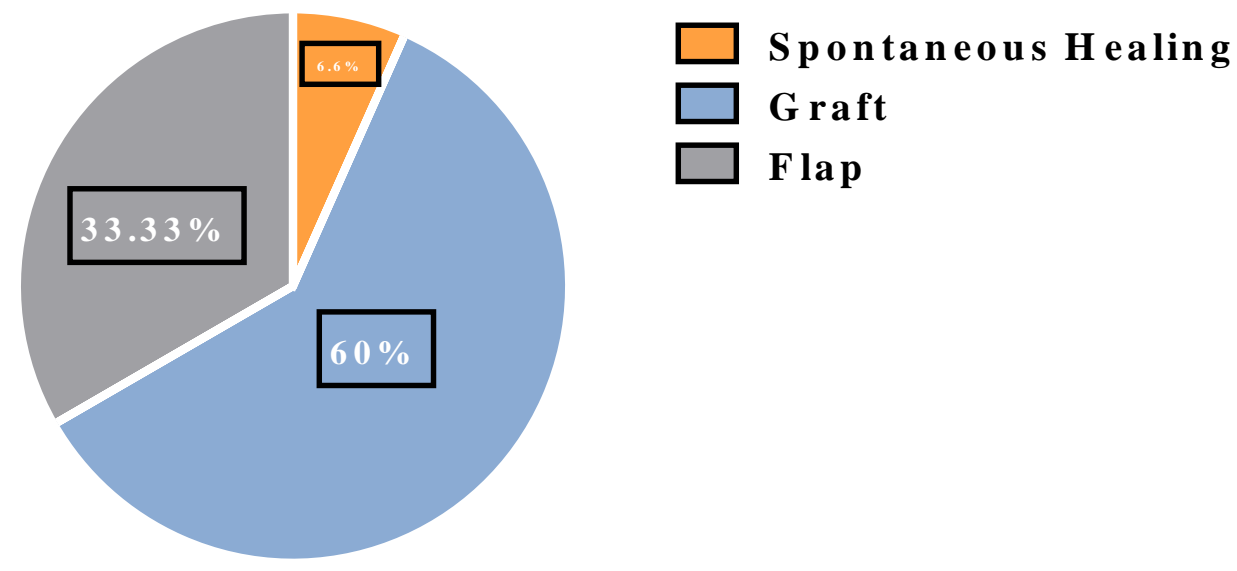

Figure (10): Pie chart displayed the fate of wounds after negative pressure therapy among the included patients

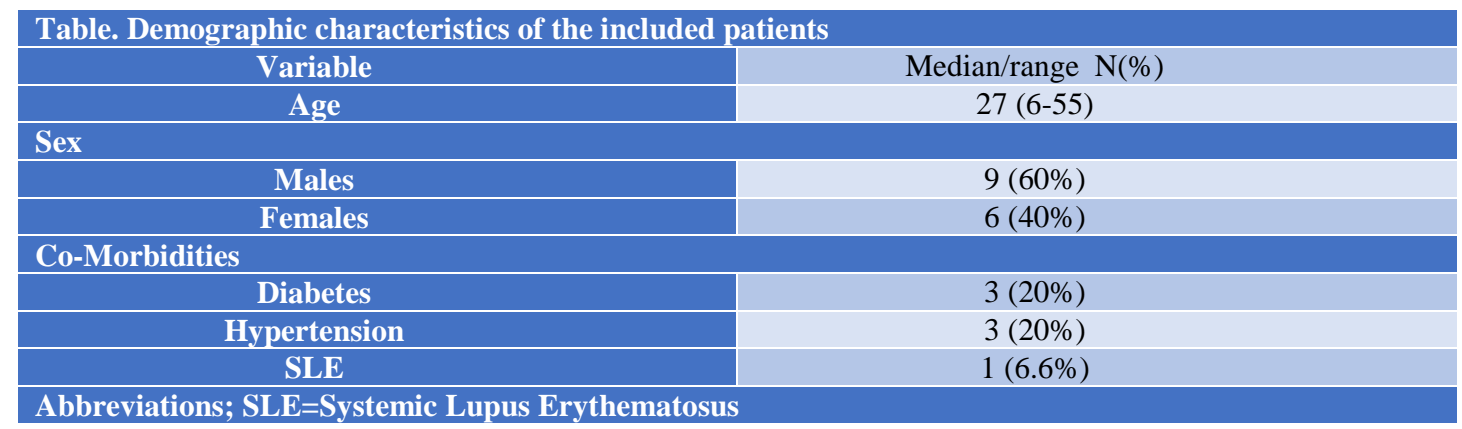

Table (2): Distribution of studied sample according to demographic data $(n=15)$

\begin{tabular}{|c|c|}
\hline Variables & $\mathbf{N}(\%)$ \\
\hline Traumatic & $8(53.3 \%)$ \\
\hline Diabetic foot & $2(13.3 \%)$ \\
\hline fascio-cutaneous flap & $1(6.6 \%)$ \\
\hline Post-abscess drainage & $2(13.3 \%)$ \\
\hline Cellulitis & $1(6.6 \%)$ \\
\hline
\end{tabular}

Table (3): The causes of lower extremity wound

\begin{tabular}{|c|c|}
\hline & $\mathbf{N}(\%)$ \\
\hline Foot & $6(40 \%)$ \\
\hline Thigh & $4(26.6 \%)$ \\
\hline Leg & $3(20 \%)$ \\
\hline Knee & $1(6.6 \%)$ \\
\hline Ankle & $1(6.6 \%)$ \\
\hline
\end{tabular}

Table (4): The sites of lower extremity wounds 
Emam, et al. Negative pressure therapy in wounds

\begin{tabular}{|c|c|c|c|}
\hline $\begin{array}{c}\text { Pre negative pressure } \\
\text { therapy }\end{array}$ & $\begin{array}{c}\text { Post negative pressure } \\
\text { therapy }\end{array}$ & $\begin{array}{c}\text { Wilcoxon Signed } \\
\text { Ranks Test }\end{array}$ & \multicolumn{2}{c|}{\begin{tabular}{c} 
P-Value \\
\hline $\mathbf{8}(\mathbf{5 3 . 3} \%)$
\end{tabular}} \\
\hline
\end{tabular}

Table (5): The pattern of wound infection pre and after negative pressure therapy.

\begin{tabular}{|c|c|}
\hline Variables & $\mathbf{N}(\%)$ \\
\hline Spontaneous healing & $1(6.6 \%)$ \\
\hline Graft & $9(60 \%)$ \\
\hline Flap & $5(33.33 \%)$ \\
\hline
\end{tabular}

Table (6): The fate of wounds after negative pressure therapy

\section{Discussion}

Healing is a complicated, interdependent process that involves complex interactions between cells, the cellular microenvironment, biochemical mediators, and extracellular matrix molecules that usually result in a functional restoration of the injured tissue. . $^{7} 8$

The goals of wound healing are to minimize blood loss, replace any defect with new tissue (granulation tissue), and restore an intact epithelial barrier as rapidly as possible. The rate of wound healing is limited by the available vascular supply and the rate of formation of new capillaries and matrix molecules. These events are heavily influenced by locally acting growth factors that affect various processes including proliferation, angiogenesis, chemotaxis and migration, gene expression, proteinases, and protein production. 9,11

Clinical applications of VAC therapy includes; diabetic foot infections, pressure ulcers, open abdominal wounds, sternal wounds, soft tissue defects after trauma, necrotizing fasciitis, hydradenitis suppurative and extravasation injury, skin graft fixation and burns.

The current study included an overall 15 patients. There were $9(60 \%)$ males and $6(40 \%)$ females with a median age of 27 (6-55) years. Out of the included patients, there were three (20\%) patients suffered from diabetes, a case $(6.6 \%)$ of systemic lupus erythromatosus. Besides that, and three (20\%) hypertensive cases .

The results of the current study revealed that among the 15 patients, There were $8(53.3 \%)$ patients had lower extremity wound as a result of trauma, two (13.3\%) patients had lower limb wound as a result of diabetic foot, one (6.6\%) patient had such wound as a sequel of fascio-cutaneous flap failure, two (13.3\%) patients had lower extremity wound after abscess drainage, whereas one (6.6\%) case had lower limb wound as a result of cellulitis .

In our cohort, the median wound size was 15 (3-30) $\mathrm{cm}^{2}$. In this concern, the most common wound site was the foot, $6(40 \%)$ patients, succeeded by thigh and legs among four $(26.6 \%)$ and three $(20 \%)$ cases, respectively. There were an equal proportion of patients who had knee and ankle wound, $6.6 \%$.(

From the 11 acute trauma manuscripts there was one randomised clinical trial 12 , one prospective comparative trial 13 one retrospective comparative study 14 and eight prospective or retrospective case series. 15 16-18 19-21 The overall number of VACtreated patients was 430 . The overall results were consensus with our result.

Ford et al. ${ }^{22}$ reported improved results in patients with chronic osteomyelitis after VAC treatment. They postulated that the negative pressure created by the VAC device facilitates antibiotic penetration from surrounding capillaries into the bone, thus controlling infection .

In contrast with chen $\mathrm{k}$ et al ${ }^{23}$ there was no statistically significant difference between the included patients regarding the pattern of wound infection pre and after negative pressure therapy .

In our study the reduction in the size of the wounds occurred in all the patients but with variations with mean reduction of $43.6 \%$ and the result consensus with chen $\mathrm{k}$ et al. ${ }^{23}$

The study of De Franzo et al18 used VAC therapy on 75 patients with open wounds of lower extremity but without osteomyelitis. They reported a rapid granulation tissue formation, reduction in bacterial count and successful wound closure in $95 \%$ of cases . In our study the trauma was the commonest cause (43.3\%) comparable to that of Ghani et al $(60 \%)$. Philbeck et al. ${ }^{24}$ reported that intermittent or cycled treatment appears more effective than continuous therapy, because intermittent cycling results in rhythmic perfusion of the tissue which is maintained because the process of capillary autoregulation is not activated. They also suggested that as cells which are undergoing mitosis must go through a cycle of rest, cellular component production and division, constant stimulation may cause the cells to ignore the stimulus and thus become ineffective. Intermittent stimulation allows the cells time to rest and prepare for the next cycle. For this reason it is suggested that cyclical negative pressure should be used clinically. 
Application of VAC is very versatile and can be used on various anatomical sites with good results. It has also been used after resection of musculoskeletal tumors and for closure of partial foot amputations ${ }^{25,26}$

\section{Conclusion}

VAC is relatively a new technique to our part of the world. It is very effective in promoting healing. It helps by reducing size of the wound and more importantly promoting granulation tissue formation. This technique is very simple to learn and practice. It is an extremely simple modality and does not require expensive equipment.

Although traditional soft tissue reconstruction may still be required to obtain adequate coverage, the use of this dressing appears to decrease their need overall. Using VAC minimise the number of local and freeflap transfers. We advocated that by using NPWT, the need for extensive plastic surgery was reduced.

\section{References}

1. Agarwal P, Kukrele R, Sharma D. Vacuum assisted closure (VAC)/negative pressure wound therapy (NPWT) for difficult wounds: A review. $J$ Clin Orthop Trauma. 2019;10(5):845-848. doi:10.1016/j.jcot.2019.06.015

2. Mutschler W, Muth C-M. Hyperbare Sauerstofftherapie in der Unfallchirurgie. Unfallchirurg. doi:10.1007/s001130050699

3. Godbout JP, Glaser R. Stress-induced immune dysregulation: implications for wound healing, infectious disease and cancer. $J$ Neuroimmune Pharmacol. 2006; 1(4):421-427. doi:10.1007/s11481-006-9036-0

4. Bishop A. Role of oxygen in wound healing. $J$ Wound Care. 2008; (9):399-402. doi:10.12968/jowc.2008.17.9.30937

5. Mouës CM, Heule F, Hovius SER. A review of topical negative pressure therapy in wound healing: sufficient evidence? Am $J$ Surg. 2011;201(4):544-556.

doi:10.1016/j.amjsurg.2010.04.029

6. Investigation P, Hepatotoxicity ACI. Asian Journal of Pharmaceutical and Health Sciences. 2011:1-5.

7. Richard A. F. Clark. The Molecular and Cellular Biology of Wound Repair. 1998; chapter, 17 page 512-520.

8. Satish L, Kathju S. Cellular and Molecular Characteristics of Scarless versus Fibrotic Wound Healing. Dermatol Res Pract. 2010;2010:1-11. doi:10.1155/2010/790234

9. Laiho M, Keski-Oja J. Growth factors in the regulation of pericellular proteolysis: a review. Cancer Res. 1989;49(10):2533-2553. http://www.ncbi.nlm.nih.gov/pubmed/2469534.

10. Tracy LE, Minasian RA, Caterson EJ. Extracellular Matrix and Dermal Fibroblast Function in the Healing Wound. Adv Wound Care (New Rochelle). 2016;5(3):119-136. doi:10.1089/wound.2014.0561Pierce GF, Vande
11. Berg J, Rudolph R, Tarpley J, Mustoe TA. Platelet-derived growth factor-BB and transforming growth factor beta 1 selectively modulate glycosaminoglycans, collagen, and myofibroblasts in excisional wounds. $A m J$ Pathol. 1991; 138(3):629-646. http://www.ncbi.nlm.nih.gov/pubmed/2000940.

12. Stannard JP, Robinson JT, Anderson ER, McGwin G, Volgas DA, Alonso JE. Negative pressure wound therapy to treat hematomas and surgical incisions following high-energy trauma. $J$ Trauma. 2006; 60(6):1301-1306. doi:10.1097/01.ta.0000195996.73186.2e

13. Shilt JS, Yoder JS, Manuck TA, Jacks L, Rushing $\mathrm{J}$, Smith BP. Role of vacuum-assisted closure in the treatment of pediatric lawnmower injuries. $J$ Pediatr Orthop. 2004; 24(5):482-487. doi:10.1097/00004694-200409000-00006

14. Yang CC, Chang DS, Webb LX. Vacuum-assisted closure for fasciotomy wounds following compartment syndrome of the leg. J Surg Orthop $A d v . \quad 2006 ; \quad 15(1): 19-23$. http://www.ncbi.nlm.nih.gov/pubmed/16603108.

15. Argenta LC, Morykwas MJ. Vacuum-assisted closure: a new method for wound control and treatment: clinical experience. Ann Plast Surg. 1997;38(6):563-76; discussion 577. http://www.ncbi.nlm.nih.gov/pubmed/9188971.

16. Schlatterer DR, Hirschfeld AG, Webb LX. Negative Pressure Wound Therapy in Grade IIIB Tibial Fractures: Fewer Infections and Fewer Flap Procedures? Clin Orthop Relat Res. 2015;473(5):1802-1811. doi:10.1007/s11999015-4140-1

17. Dedmond BT, Kortesis B, Punger K, et al. The use of negative-pressure wound therapy (NPWT) in the temporary treatment of soft-tissue injuries associated with high-energy open tibial shaft fractures. J Orthop Trauma. 2007;21(1):11-17. doi:10.1097/BOT.0b013e31802cbc54

18. DeFranzo AJ, Argenta LC, Marks MW, et al. The use of vacuum-assisted closure therapy for the treatment of lower-extremity wounds with exposed bone. Plast Reconstr Surg. 2001;108(5):1184-1191. doi:10.1097/00006534200110000-00013

19. Herscovici D, Sanders RW, Scaduto JM, Infante A, DiPasquale T. Vacuum-assisted wound closure (VAC therapy) for the management of patients with high-energy soft tissue injuries. J Orthop Trauma. 2003; 17(10):683-688. doi:10.1097/00005131-200311000-00004

20. Labler L, Trentz O. The use of vacuum assisted closure (VAC) in soft tissue injuries after high energy pelvic trauma. Langenbeck's Arch Surg. 2007;392(5):601-609. doi:10.1007/s00423-0060090-0

21. Leininger BE, Rasmussen TE, Smith DL, Jenkins $\mathrm{DH}$, Coppola C. Experience with wound VAC and delayed primary closure of contaminated soft tissue injuries in Iraq. $J$ Trauma. 2006; 61(5):1207-1211. doi:10.1097/01.ta.0000241150.15342.da

22. Ford CN, Reinhard ER, Yeh D, et al. Interim analysis of a prospective, randomized trial of vacuum-assisted closure versus the healthpoint system in the management of pressure ulcers. Ann 


\section{Emam, et al. Negative pressure therapy in wounds}

Plast Surg. 2002; 49(1):55-61; discussion 61. doi:10.1097/00000637-200207000-00009

23. Chen S-Z, Li J, Li X-Y, Xu L-S. Effects of vacuum-assisted closure on wound microcirculation: an experimental study. Asian J Surg. 2005; 28(3):211-217. doi:10.1016/S10159584(09)60346-8

24. Philbeck TE, Whittington KT, Millsap MH, Briones RB, Wight DG, Schroeder WJ. The clinical and cost effectiveness of externally applied negative pressure wound therapy in the treatment of wounds in home healthcare Medicare patients. Ostomy Wound Management. 1999; 45(11):41-50.

25. Bickels J, Kollender Y, Wittig JC, Cohen N, Meller I, Malawer MM. Vacuum-assisted wound closure after resection of musculoskeletal tumors. Clin Orthop Relat Res. 2005;441:346-350. doi:10.1097/01.blo.0000180450.21350.3e

26. Armstrong DG, Lavery LA, Boulton AJM Negative pressure wound therapy via vacuumassisted closure following partial foot amputation: what is the role of wound chronicity? Int Wound J. 2007;4(1):79-86. doi:10.1111/j.1742481X.2006.00270.x 